\title{
The Cost of Waiting on an Orthopaedic Waiting List: a scoping review
}

\author{
J Morris, A Twizeyemariya and K Grimmer
}

\begin{abstract}
Background: Approximately 30\% Australians suffer from arthritis and other musculoskeletal disorders. From 2003-2033 there is a predicted $223 \%$ increase in expenditure on health management of musculoskeletal disorders. There is evidence of increasing prevalence of orthopaedic complaints, in longer waiting lists for specialist consultations in public hospital outpatient clinics. Little is known about the costs and ramifications of waiting for orthopaedic consultations.

Aim: Establish what is known about the direct and indirect costs of being placed on a waiting list for an orthopaedic consultation.

Method: Patient and Outcome search strategy of Medline, Embase, Pubmed, NHS Economic evaluation database (NHS-EED) from each database inception date. Handsearching of reference lists of included papers also occurred. A realist synthesis framework underpinned the review, using a ubiquitous patient journey to map available literature on the impact of waiting. Hierarchy of evidence was reported using NHMRC criteria and articles critically appraised using either the PEDRo or CASP criteria (relevant to the design). A purpose-built data extraction instrument was developed.
\end{abstract}

Results: We identified 786 studies, of which 139 were relevant, including a systematic review (Hoogeboom et al) with 15 included articles which were added to the list of eligible papers (and the review itself deleted), leaving 153 included articles; 17 were relevant to the review. Fourteen papers reported on quality of life and four reported on costs, two of these papers reported on both and all were of low to moderate quality. The research was not based on a comprehensive understanding of the stages of waiting, and there were inconclusive outcomes for quality of life and cost.

Conclusion: There is scant evidence of the impact on quality of life and costs of waiting for orthopaedic outpatient appointments. Future research should aim for improved methodological quality and use patientfocused quality of life measures, and validated measures of cost.

Abbreviations: NHMRC - National Health and Medical Research Council; PROMS - Patient Related Outcome Measures; QoL - Quality of Life; WOMAC - Western Ontario and McMaster Universities Osteoarthritis Index; YLD - Years Lived With Disability.

Key words: Orthopaedics; waiting list; costs; scoping review.

\section{Joanne Morris}

International Centre for Allied Health Evidence

University of South Australia

Adelaide, South Australia, Australia.

Physiotherapy Department

Canberra Hospital

Canberra, Australian Capital Territory, Australia.

\section{Asterie Twizeyemariya}

International Centre for Allied Health Evidence

University of South Australia

Adelaide, South Australia, Australia.

\section{Karen Grimmer}

International Centre for Allied Health Evidence

University of South Australia

Adelaide, South Australia, Australia.

Correspondence:

Joanne.Morris@canberra.edu.au 


\section{Introduction}

In May 2015, the Australian Institute of Health and Welfare (AlHW) reported that $28 \%$ of Australians (approximately 6.1 million people), suffered from arthritis and other similar degenerative musculoskeletal disorders. [1] Moreover, musculoskeletal disorders were identified in 2010 as contributing $21.3 \%$ to worldwide years lived with disability (YLDs), this being second only to mental and emotional disorders. [2] Hip and knee osteoarthritis alone are reported to be the 11th highest contributor to global disability. [3] Gross explored predicted healthcare expenditure in Australia from 2003 to 2033, by disease. He documented a $223 \%$ anticipated increase in healthcare expenditure for musculoskeletal disorders, citing an ageing population and an increase in the incidence of disease as key drivers for escalating costs. [4] The increasing prevalence of orthopaedic conditions has been noted since as escalating use of hospital outpatient orthopaedic services, [5] particularly noticeable for individuals who require public health system management. $[6,7,8,9]$ One way of managing the increasing volume of individuals requiring orthopaedic consultations in the public sector is to place them on waiting lists. In Australia there are two avenues for accessing healthcare, including orthopaedic care, via the public health system or through private health facilities. The public health system in relation to specialist orthopaedic care is fully funded through the Medicare system, therefore the patient is not required to pay anything for this care, including appointments and subsequent treatment (including surgery) and investigations. The public health facilities are managed at state level and therefore there state-bystate variations in process, procedures and definitions are inevitable.

The private health system can be accessed in two ways: the patient can fully fund all aspects of care or if they have private health insurance they can seek reimbursement through their private fund. Invariably in private healthcare the patient is subject to out of pocket expenses regardless of their level of cover.

There is consistent evidence of increasing numbers of people on public hospital waiting lists for orthopaedic consultations, and lengthening waiting periods for orthopaedic/ musculoskeletal surgery. $[10,11,12]$ Outpatients can wait for months from first being placed on the hospital waiting list, to having their first orthopaedic consultation, and there is usually additional waiting time following that, for treatment to be provided. For some patients, the time delay between initial consultation and treatment could be
12 or more months. [13] There is also increasing evidence that whilst waiting, patients incur significant out-of-pocket costs for formal or informal care, in order to manage their condition. [5] These costs are direct and indirect. Direct costs could include medication, GP appointments, accessing further tests, travel to appointments, loss of wages, allied health visits, formal care and home adaptations, whilst indirect costs may be in the form of lost time at work or informal care arrangements. [14,5] There are also potential societal impacts, in the form of use of government funded care (residential or home-based care), loss of tax revenue, social support and hospitalisation. [5] In addition to the economic burden of waiting there is the potential for health deterioration, altered capacity to perform usual activities of daily living, and reduced capacity to be productive at home and/or in society. $[15,16]$ Deterioration in health state associated with musculoskeletal disease is considered to impact on many facets of well-being, general health, physical, social and mental health, and as such, produces barriers to participation in daily activities. [5]

Health departments and public hospitals particularly in the United Kingdom and in Australia have been exploring alternative workforce models of care to meet the increasing need for health services for patients with chronic orthopaedic/musculoskeletal complaints. $[17,18,8,19,11,20]$ This includes new pathways of care and changes in the traditional models of care within the health workforce. [7,21] A common alternative model of care is senior allied health professionals performing roles traditionally undertaken by specialist medical practitioners, for example a specialist physiotherapist assessing, diagnosing and managing patients referred to an orthopaedic consultant. The purpose of these initiatives is to streamline and optimise use of expensive medical consultant time, minimise time 'wasted' on waiting lists, and provide alternative earlier care options for patients instead of simply 'waiting'. $[7,8]$

Patients attending outpatient orthopaedic clinics are usually referred by general medical practitioners, or from other outpatient clinics. Within Australia, public hospital orthopaedic specialist consultation is often the preferred pathway to care, particularly when patients do not have private health insurance. Most public hospital orthopaedic waiting lists reflect a range of orthopaedic conditions affecting lower and upper limb joints, and the spine. [20] Increasing numbers of patients on orthopaedic outpatient waiting lists mean longer wait time for most people, [11] and potentially greater costs. 
Figure 1. Realist synthesis framework of ubiquitous patient journey

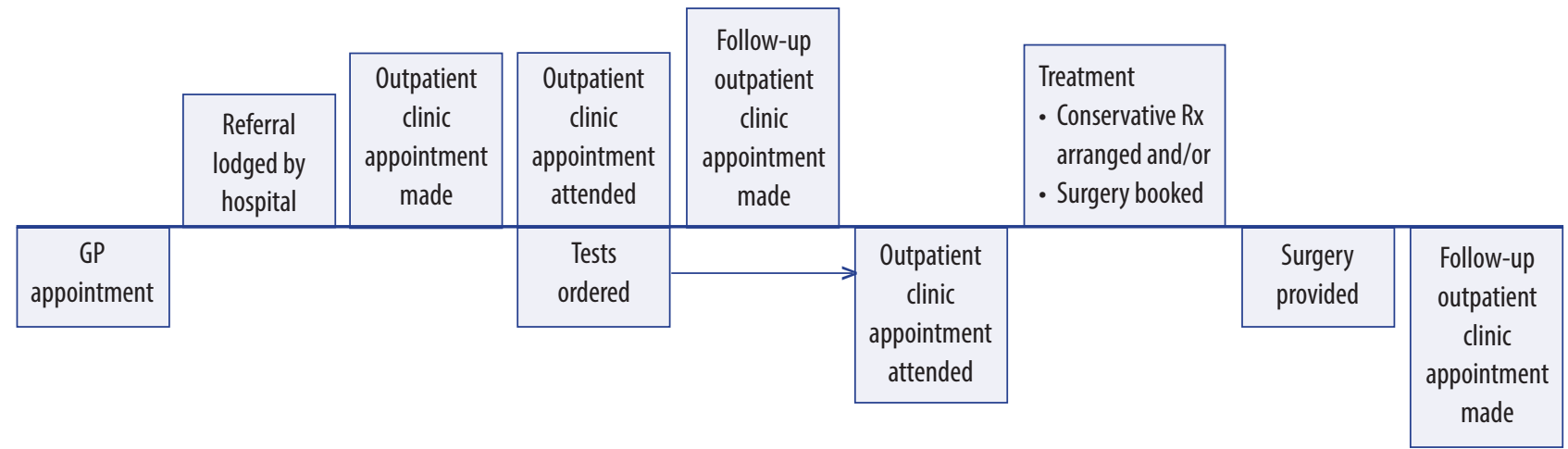

This paper reports on a systematic scoping review of the literature undertaken with the aim of identifying what has been written about the costs of waiting (both direct and indirect) and the ramifications of waiting on quality of life (QoL).

\section{Methods}

Study design: A systematic scoping review of the international peer-reviewed literature was undertaken to identify the amount and type of research published in this area, and provide the first known evidence scan of what has been published to date on the cost and quality of life impact of waiting for an orthopaedic consultation.

Review registration: This review was registered with PROSPERO (CRD42016047332). PROSPERO is an international database used to register systematic reviews prior to the review being commenced. The purpose of PROSPERO is to provide a comprehensive list of systematic reviews in which the key characteristics of the review are permanently recorded to avoid repetition and reporting bias.

Reporting standard: This review was reported in line with the Joanna Briggs Institute methodology for scoping reviews. [22] This provides a rigorous framework in the planning, development, study selection, collation of results and reporting to ensure that the most information is gleaned from the search and reported in a systematic, reproducible way.

Review purpose: The purpose of this review was to systematically identify and classify all freely available, relevant peer-reviewed literature which reported on the impact of waiting for consultation/treatment for patients with an orthopaedic/musculoskeletal complaint.

Framework of the review: We undertook this review within the context of a usual patient journey through the outpatient orthopaedic consultation process. This framework was based on a Realist Synthesis approach [23] which assists systematic review findings to be mapped for complex situations. Defining a waiting list is one such complex situation. To establish the realist synthesis framework, we undertook an informal overview of the literature about the orthopaedic outpatient journey, and found that there is a growing body of literature over the last decade on waiting list management. We constructed a map of the literature which reports on aspects of patient journeys (entering, being on, and leaving, an orthopedic outpatient waiting list). We proposed a ubiquitous patient journey (Figure 1) which outlines our understanding of the stages of waiting. This journey was used as an aid to describing the relevance of the literature identified in this review, to aspects of the journey.

Search strategy: The search was conducted in March 2016 and updated in September 2016. A PO search strategy (Participants, Outcomes) was applied to identify relevant articles. Library databases of Medline, Embase, Pubmed, and NHS Economic evaluation database (NHS-EED) were

\section{Table 1: Search terms}

\begin{tabular}{|ll|}
\hline P & Orthopedics/musculoskeletal/orthop?edic* \\
\hline C & $\begin{array}{l}\text { Outpatient*/Ambulatory Care/clinic visit* } \\
\text { Surgery/treatment AND } \\
\text { Waiting Lists/or wait* }\end{array}$ \\
O & Not relevant \\
& $\begin{array}{l}\text { Analysis/Cost Savings/ Cost of Illness/Cost } \\
\text { Analysis } \\
\text { Quality of life/function* status/ productivity/ } \\
\text { work/sick leave }\end{array}$ \\
S & $\begin{array}{l}\text { No restriction on the study design } \\
\text { Inpatients, not Orthopaedic/musculoskeletal } \\
\text { patients, paediatric } \\
\text { Conference papers and abstract only }\end{array}$ \\
\hline
\end{tabular}


searched, from each database inception date. Broad search terms and inclusion criteria were applied in an attempt to identify all relevant papers related patients with an orthopaedic/musculoskeletal complaint waiting for specialist consultation/treatment. MESH headings or Boolean operators were used with the search terms, relevant to the database being searched. The search terms are outlined in Table 1.

Additional searching: The reference lists of the papers identified through the database searches were handsearched to identify additional papers which were relevant, but which had not been identified from the literature search.

Population: Adult patients (18 years and over) with an orthopaedic and/or musculoskeletal complaint for which they had been referred to an outpatient clinic for specialist consultation/ treatment. No limitations were applied in terms of diagnostic categories.

Outcomes: Impact of waiting was explored in terms of cost, such as a costbenefit analysis, to the patient (in terms of productivity, loss time from work, direct health costs incurred), healthcare providers (visits to GPs, hospitalisations, community care) and society (loss of tax revenue) and the impact on the patient's quality of life, function and social integration.

Study identification: The titles and abstracts of each potentially relevant paper were screened by two researchers (JM, AT) for relevance to the study purpose. In the case of dispute, a third author (KG) arbitrated.

Eligible studies: Studies of any hierarchy of evidence were considered for inclusion as long as they met the $P$ and $O$ criteria, and were in English language. Thus studies were included if they explored any impact of waiting for orthopaedic/musculoskeletal consultation and/or treatment for adults.

Exclusion criteria: Articles were excluded if they did not report on the impact of waiting for management of an orthopaedic/musculoskeletal complaint by a specialist, if they described children (younger than 18 years), if they did not report on quality of life and/or cost impacts, were not available in full text, and were not in English.

Hierarchy of evidence: Hierarchy of evidence was reported using National Health and Medical Research Council (NHMRC) criteria relevant to the study question. [24] This provides a comprehensive and structure way of grading evidence according to the research design. We anticipated that most studies would be classified using the aetiology hierarchy, as they would be largely observational (what happened as a result of waiting). The NHMRC evidence hierarchy is subdivided into five areas that mean the grading system is adaptable to different research questions, aetiology hierarchy refers to studies that explore causation of diseases or conditions.

Critical appraisal: This was undertaken by two independent reviewers using the relevant appraisal tool. Any level II studies were critically appraised with Physiotherapy Evidence Database [25] criteria, and the Level III-3 and IV studies were critically appraised with the Critical Appraisal Skills Program (CASP). [26] Critical appraisal scores were compared, and disagreements discussed and resolved.

Data extraction: Data was extracted by two reviewers working together (JM, AT). Data was extracted into a custombuilt MS Excel sheet to allow for easy comparison between the outcomes from the extracted studies. Extracted data included country of research, patient demographics, health condition, study design, waiting list description, where in the patient journey the research was conducted (see Figure 1 ), measures of quality of life or cost. Cost data was further reported as types of cost.

\section{Results}

The search identified 786 potentially eligible studies (see Figure 2). There were 393 duplicates, and another 254 articles were removed, after considering title and abstract, as not meeting the inclusion criteria. This left 139 potentially relevant articles.

Handsearching: Included in these potentially relevant articles was a systematic review [27] which summarised 15 primary articles. After debate, it was decided that, as aims of our review differed from the Hoogeboom et al aims, we should consider the 15 individual papers in the Hoogeboom review, rather than the review itself. [27] No other relevant references were identified from handsearching the remaining included papers' reference lists.

Search results: The search output was adjusted from 139 potentially relevant papers (including Hoogeboom et al) to 138 papers (excluding the Hoogeboom review) plus the 15 component papers from the Hoogeboom et al review, giving 153 potentially relevant papers. Using the Pawson realist synthesis framework (Figure 1) to map the reported outcomes from the potentially relevant papers identified 17 papers which met the review's inclusion criteria (excluding 135). 
Figure 2:
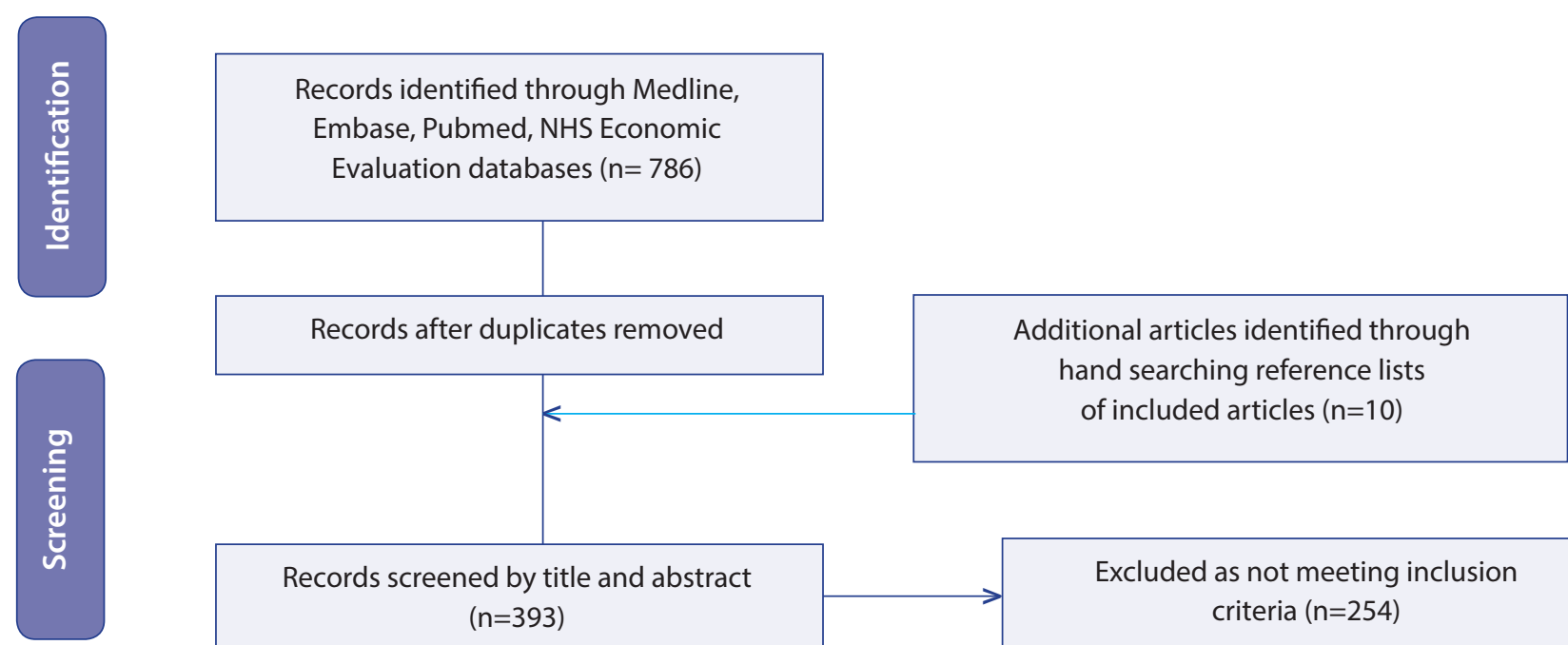

Excluded as not meeting inclusion $(n=393)$ criteria $(n=254)$

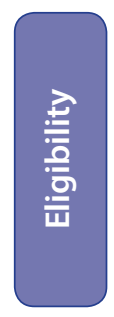

Papers assessed by full text for eligibility $(n=139)$ (adjusted to 153 papers

by addition of the 15 component papers in Hoogeboom et al 2009 (SR) and removal of Hoogeboom et al

Excluded as not reporting on outcomes related to costs, or quality of life, whilst waiting $\mathrm{N}=137$ (inc 5 components studies in Hoogeboom et al 2009)

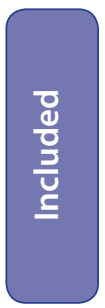

Full text articles reporting on cost and/ or quality of life measures during any aspect of the waiting period $(n=17)$

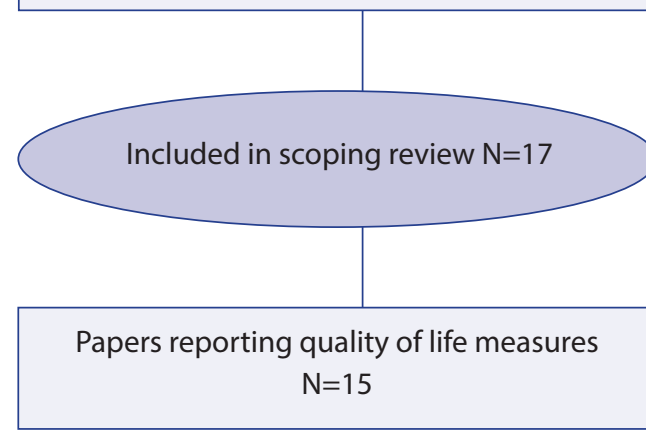

Reporting on any element of costing $\mathrm{N}=4$

- There were two included papers which reported on both costs and quality of life; March et al; Fielden et al. $[28,29]$

- The 13 included papers that reported only on quality of life measures included Ackerman et al; Ahmas and Konduru; Chakravarty et al; Desmeules et al; Desmeules et al; Hirvonen et al; Kapstad et al; Kelly et al; McHugh et al; Nilsdotter and Lohmander; Nunez et al; Ostendorf et al; Pace et al. [31-41,16]

- The two included papers that reported only on costs comprised Rolfson et al and Tuominen et al. [14,42]
Hierarchy and quality of evidence: The included studies when graded according to the NHMRC hierarchy of evidence, demonstrated that the research in this area is generally lowlevel aetiology studies, and III-3 uncontrolled prospective studies (see Table 2) and therefore of relatively low quality. Table 2 also reports critical appraisal scores.

\section{Data descriptions}

Countries where research was conducted: The studies were from a wide range of developed world countries (Canada, Finland, Australia, Holland, Spain, New Zealand, Sweden, Norway and the United Kingdom). None came 
Table 2: Aetiology hierarchy

\begin{tabular}{|c|c|c|c|}
\hline QUALITY OF LIFE PAPERS & NHMRC & $\begin{array}{l}\text { CRITICAL APPRAISAL - } \\
\text { CASP COHORT TOOL }\end{array}$ & PEDRO \\
\hline Desmeules et al 2010a & III-3 & $12 / 14$ & N/A \\
\hline Desmeules et al 2010b & III-3 & $12 / 14$ & N/A \\
\hline Hirvonen et al 2009 & II & N/A & $8 / 11$ \\
\hline Ackerman et al 2011 & III-3 & $12 / 14$ & N/A \\
\hline Ostendorf et al 2004 & III-3 & $11 / 14$ & $\mathrm{~N} / \mathrm{A}$ \\
\hline Fielden et al 2005 & III-3 & $9 / 14$ & N/A \\
\hline Nunez et al 2006 & III & N/A & $7 / 11$ \\
\hline March et al 2002 & III-3 & $9 / 14$ & N/A \\
\hline Ahmas \& Konduru 2007 & III-3 & $6 / 14$ & N/A \\
\hline Chakravarty et al 2005 & IV & $9 / 14$ & N/A \\
\hline Kapstad et al 2007 & III-3 & $11 / 14$ & N/A \\
\hline Kelly et al 2001 & III-3 & $13 / 14$ & N/A \\
\hline McHugh et al 2007 & III-3 & $13 / 14$ & N/A \\
\hline Nilsdotter \& Lohmander 2002 & III-3 & $11 / 14$ & N/A \\
\hline Pace et al 2006 & III-3 & $12 / 14$ & N/A \\
\hline COST PAPERS & & $\begin{array}{l}\text { CRITICAL APPRAISAL - } \\
\text { CASP ECONOMIC TOOL }\end{array}$ & PEDRO \\
\hline Tuominen et al 2009 & II & N/A & $8 / 11$ \\
\hline March et al 2002 & III-3 & $9 / 14$ & N/A \\
\hline Fielden et al 2005 & III-3 & $9 / 14$ & N/A \\
\hline Rolfson et al 2012 & III & $9 / 14$ & $\mathrm{~N} / \mathrm{A}$ \\
\hline
\end{tabular}

from developing countries. Whilst all countries in the studies have established healthcare systems, there were significant differences between them in terms of how healthcare was delivered. This constrained comparison of findings.

Study periods: There was wide variability in the periods of research, the majority reported a 12-18 month recruitment of patients, whilst some recruited for over three years. Mapping the data against the realist synthesis ubiquitous patient journey (outlined Figure 1), there was a lack of consistency in the period of time over which data was collected making comparison of findings difficult. Figure 3 outlines the included papers against the realist synthesis patient journey.

Musculoskeletal conditions: The included studies reported only on patients with osteoarthritis of the hip or knee, in particular there is a significant emphasis on patients awaiting total hip and knee replacements, and the period following surgery. In terms of the patients included in the reported studies, one striking issue is the lack of standardised measures used to add patients to the surgical waiting list. Only two papers [38,39] described a standardised grading system for severity of joint disease, one using the 
Figure 3: Papers across the spectrum of waiting

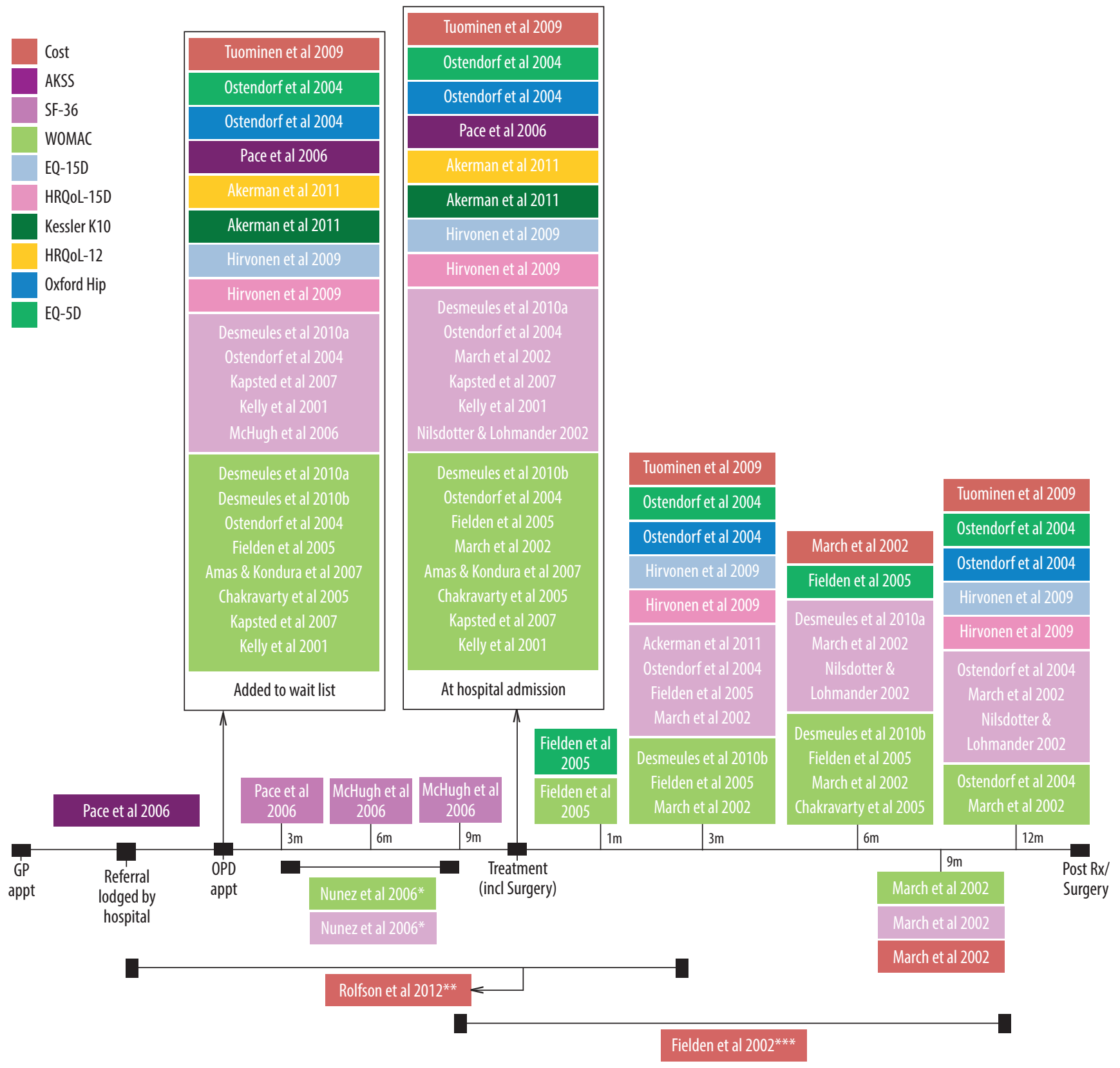

Kellgren-Lawrence grading system $[43,44]$ and the other the Osteoarthritis Research Society International criteria whilst the remaining papers only reported that the patients had severe enough arthritis to warrant a joint replacement.

Waiting times: This was described variably, particularly what was considered to be long, medium and short term waiting periods and at what time points in the waiting period the measures are taken. Again the realist synthesis framework outlined in Figure 1 assisted in the comparison between studies. Fifteen papers explored the impact of the pre-operative waiting period on the outcome of surgery in some cases up to twelve months post-surgery. Only two papers $[14,41]$ reported on the waiting period from point of GP referral into the specialist service. For the remaining papers, the start of the waiting period was deemed to be at the point the patient was placed on a surgical waiting list for a total hip or total knee replacement, depending on the study. See Figure 3.

Quality of life: Table 3 reports of the different quality of life measures reported in the included papers. The most commonly reported outcome measures were Short Form (36) Health Survey (SF-36) [45] and the Western Ontario and McMaster Universities Osteoarthritis Index (WOMAC). [46] There were inconsistent findings about the impact of 
Table 3: Quality of life outcome measures reported

\begin{tabular}{|c|c|c|c|c|c|c|c|c|c|c|c|c|c|c|}
\hline & $\begin{array}{l}\text { QUALITY OF } \\
\text { LIFE STUDIES }\end{array}$ & COUNTRY & YEAR & $\begin{array}{l}\text { BODY } \\
\text { PART }\end{array}$ & SF36 & WOMAC & $\begin{array}{c}\text { WOMAC OF } \\
\text { CONTRALATERA } \\
\text { L KNEE }\end{array}$ & EQ-15 D & \begin{tabular}{|c|} 
MODIFIED \\
HARRIS \\
HCP \\
SCORE
\end{tabular} & $\begin{array}{c}\text { OXFORD } \\
\text { HIP } \\
\text { SCORE }\end{array}$ & $\begin{array}{c}\text { KESSLER } \\
\text { PSYCHOLOGICAL } \\
\text { DIITRESS } \\
\text { SCALE }\end{array}$ & $\begin{array}{c}\text { HRQOL } \\
\text { ITEM } \\
\text { INSTRUMENTS }\end{array}$ & EQ-5 D & $\begin{array}{l}\text { AMERICAN } \\
\text { KNEE } \\
\text { SOCIETY } \\
\text { SCALE }\end{array}$ \\
\hline 1 & $\begin{array}{l}\text { Desmeules } \\
\text { et al } 2010 \mathrm{a}\end{array}$ & Canada & 2006-7 & Knee & $\checkmark$ & $\checkmark$ & $\checkmark$ & $x$ & $x$ & $x$ & $x$ & $x$ & $x$ & $x$ \\
\hline 2 & $\begin{array}{l}\text { Desmeules } \\
\text { et al 2010b }\end{array}$ & Canada & $2006-7$ & Knee & $\checkmark$ & $\checkmark$ & $\checkmark$ & $x$ & $x$ & $x$ & $x$ & $x$ & $x$ & $x$ \\
\hline 3 & $\begin{array}{l}\text { Hirvonen } \\
\text { et al } 2009\end{array}$ & Finland & $2002-3$ & Hip & $x$ & $x$ & $x$ & $\checkmark$ & $\checkmark$ & $x$ & $x$ & $x$ & $x$ & $x$ \\
\hline 4 & $\begin{array}{l}\text { Ackerman } \\
\text { et al } 2011\end{array}$ & Australia & $2002-5$ & $\begin{array}{l}\text { Hip \& } \\
\text { knee }\end{array}$ & $x$ & $x$ & $x$ & $x$ & $x$ & $x$ & $\checkmark$ & $\checkmark$ & $x$ & $x$ \\
\hline 5 & $\begin{array}{l}\text { Ostendorf } \\
\text { et al } 2004\end{array}$ & Holland & $\begin{array}{l}\text { Apr } 1997 \\
\text { Sept } 2000\end{array}$ & $\begin{array}{c}\text { Hip } \\
\text { awaiting } \\
\text { THR }\end{array}$ & $\checkmark$ & $\checkmark$ & $x$ & $x$ & $x$ & $x$ & $x$ & $x$ & $x$ & $x$ \\
\hline 6 & $\begin{array}{l}\text { Nunez et al } \\
2006 \text { Spain }\end{array}$ & Spain & $\begin{array}{l}\text { Feb-0ct } \\
2001\end{array}$ & $\begin{array}{c}\text { Knee } \\
\text { awaiting } \\
\text { TKR }\end{array}$ & $\checkmark$ & $\checkmark$ & $x$ & $x$ & $x$ & $x$ & $x$ & $x$ & $x$ & $x$ \\
\hline 7 & $\begin{array}{l}\text { Fielden et } \\
\text { al } 2005\end{array}$ & $\begin{array}{c}\text { New } \\
\text { Zealand }\end{array}$ & $\begin{array}{l}\text { Apr 1997- } \\
\text { Mar } 2002\end{array}$ & $\begin{array}{c}\text { Hip } \\
\text { awaiting } \\
\text { THR }\end{array}$ & $x$ & $\checkmark$ & $x$ & $x$ & $x$ & $x$ & $x$ & $x$ & $\checkmark$ & $x$ \\
\hline 8 & $\begin{array}{l}\text { March et al } \\
2002\end{array}$ & Australia & 1994-95 & $\begin{array}{l}\text { Hip \& } \\
\text { knee }\end{array}$ & $\checkmark$ & $\checkmark$ & $x$ & $x$ & $x$ & $x$ & $x$ & $x$ & $x$ & $x$ \\
\hline 9 & $\begin{array}{l}\text { Ahmad \& } \\
\text { Konduru }\end{array}$ & UK & $\begin{array}{l}\text { June 2003- } \\
\text { Dec 2004 }\end{array}$ & Knee & $x$ & $\checkmark$ & $x$ & $x$ & $x$ & $x$ & $x$ & $x$ & $x$ & $x$ \\
\hline 10 & $\begin{array}{l}\text { Chakravarty } \\
\text { et al } 2005\end{array}$ & UK & Unknown & Hip & $x$ & $\checkmark$ & $x$ & $x$ & $x$ & $x$ & $x$ & $x$ & $x$ & $x$ \\
\hline 11 & $\begin{array}{l}\text { Kapstad } \\
\text { et al } 2007\end{array}$ & Norway & $\begin{array}{l}\text { June 2003- } \\
\text { June } 2004\end{array}$ & $\begin{array}{l}\text { Hip \& } \\
\text { Knee }\end{array}$ & $\checkmark$ & $\checkmark$ & $x$ & $x$ & $x$ & $x$ & $x$ & $x$ & $x$ & $x$ \\
\hline 12 & $\begin{array}{l}\text { Kelly et al } \\
2001\end{array}$ & Canada & $\begin{array}{l}\text { Dec 1995- } \\
\text { Jan } 1997\end{array}$ & $\begin{array}{l}\text { Hip \& } \\
\text { Knee }\end{array}$ & $\checkmark$ & $\checkmark$ & $x$ & $x$ & $x$ & $x$ & $x$ & $x$ & $x$ & $x$ \\
\hline 13 & $\begin{array}{l}\text { McHugh et al } \\
2006\end{array}$ & UK & $\begin{array}{l}\text { May-Nov } \\
2003\end{array}$ & $\begin{array}{l}\text { Hip \& } \\
\text { Knee }\end{array}$ & $\checkmark$ & $x$ & $x$ & $x$ & $x$ & $x$ & $x$ & $x$ & $x$ & $x$ \\
\hline 14 & $\begin{array}{c}\text { Nilsdotter \& } \\
\text { Lohmander } \\
2002\end{array}$ & Sweden & \begin{tabular}{|c} 
Feb 1997- \\
Oct 1998
\end{tabular} & $\begin{array}{l}\text { Hip \& } \\
\text { Knee }\end{array}$ & $\checkmark$ & $x$ & $x$ & $x$ & $x$ & $x$ & $x$ & $x$ & $x$ & $x$ \\
\hline 15 & $\begin{array}{l}\text { Pace et al } \\
2005\end{array}$ & UK & $\begin{array}{l}\text { Jan } 2000- \\
\text { May } 2003\end{array}$ & Knee & $x$ & $x$ & $x$ & $x$ & $x$ & $x$ & $x$ & $x$ & $x$ & $x$ \\
\hline
\end{tabular}

waiting on QoL. Two studies reported that some patients have improvements in their symptoms whilst waiting for surgery, [30,32] whilst four studies reported no change for some patients $[36,32,35,38]$ whilst five studies reported worsening QoL. [16,33,30,37,41]

What is also unclear is which patients are likely to deteriorate and which are likely to stay the same or improve. Knapstad et al reported deterioration in stiffness and physical function in those patients awaiting a total knee replacement, in their study patients who were married/cohabiting demonstrated greater deterioration than those who were single/widowed, no other predisposing factors for deterioration could be established. [35] There is some evidence [31,32] that younger patients will deteriorate faster than older patients. There was also evidence to suggest that the length of wait pre-operatively negatively impacts on recovery operatively in terms of pain, function and QoL. [16,33]

Cost information: Table 4 reports the cost information recorded in the included papers reported under the broad categories of healthcare costs, community costs, informal care costs and society costs. 
Table 4: Cost parameters reported

\begin{tabular}{|c|c|c|c|c|c|c|c|c|c|c|c|c|c|c|c|}
\hline & \multirow[t]{2}{*}{ PAPER } & \multirow[t]{2}{*}{ COUNTRY } & \multirow[t]{2}{*}{ YEAR } & \multirow{2}{*}{$\begin{array}{l}\text { BODY } \\
\text { PART }\end{array}$} & \multicolumn{4}{|c|}{ HEALTHCARE COSTS } & \multicolumn{3}{|c|}{ COMMUNITY COSTS } & \multirow{2}{*}{\multicolumn{2}{|c|}{$\begin{array}{l}\text { PERSONAL EXPENSES/ } \\
\text { INFORMAL CARE }\end{array}$}} & \multirow{2}{*}{\multicolumn{2}{|c|}{ PRODUCTIVITY LOSS }} \\
\hline & & & & & $\begin{array}{l}\text { PHARMA- } \\
\text { CEUTICAL }\end{array}$ & $\begin{array}{l}\text { HEALTH- } \\
\text { CARE }\end{array}$ & TESTS & $\begin{array}{l}\text { HOSPITAL } \\
\text { CARE }\end{array}$ & $\begin{array}{l}\text { TRANS- } \\
\text { PORT \& }\end{array}$ & $\begin{array}{l}\text { HOME } \\
\text { HELP }\end{array}$ & $\begin{array}{c}\text { HOME } \\
\text { MODIF- } \\
\text { ICATIONS }\end{array}$ & & & & \\
\hline 1 & $\begin{array}{l}\text { Fielden } \\
\text { et al } 2005\end{array}$ & $\begin{array}{c}\text { New } \\
\text { Zealand }\end{array}$ & $\begin{array}{l}\text { Apr 1999- } \\
\text { Mar } 2002\end{array}$ & $\begin{array}{c}\text { Hip } \\
\text { waiting } \\
\text { THR }\end{array}$ & $\checkmark$ & $x$ & $x$ & $x$ & $x$ & $x$ & $x$ & \multicolumn{2}{|c|}{$\begin{array}{l}\text { Private expense paid } \\
\text { for medical care (user } \\
\text { charges, privately } \\
\text { funded care, travel } \\
\text { costs and paid help) }\end{array}$} & & $\begin{array}{c}\text { Time away } \\
\text { from work } \\
\text { or casual } \\
\text { activity }\end{array}$ \\
\hline 2 & Rolfson & Sweden & 0ct 2005- & Hip & $\checkmark$ & $\begin{array}{l}\text { GP visit } \\
\text { physio- } \\
\text { therapy }\end{array}$ & $x$ & $\begin{array}{c}\text { Hospital } \\
\text { in ward } \\
\text { care }\end{array}$ & $\begin{array}{c}\text { Transport } \\
\text { for } \\
\text { disabled }\end{array}$ & $\checkmark$ & $\sqrt{ }$ & $\begin{array}{c}\text { Value of } \\
\text { lost leisure } \\
\text { by } \\
\text { caregivers }\end{array}$ & $\begin{array}{l}\text { Value of } \\
\text { time away } \\
\text { from work } \\
\text { by } \\
\text { caregivers }\end{array}$ & $\begin{array}{l}\text { Disability } \\
\text { pension }\end{array}$ & Sick leave \\
\hline 3 & $\begin{array}{l}\text { Tuominen } \\
\text { et al } 2009\end{array}$ & Finland & $\begin{array}{l}\text { Aug 2002- } \\
\text { Nov } 2003\end{array}$ & Hip & $\checkmark$ & $x$ & $x$ & $x$ & $x$ & $x$ & $x$ & $x$ & $x$ & $x$ & $x$ \\
\hline 4 & $\begin{array}{c}\text { March } \\
\text { et al } 2011\end{array}$ & Australia & 1994-99 & $\begin{array}{l}\text { Hip \& } \\
\text { knee }\end{array}$ & \begin{tabular}{l}
\multicolumn{1}{c}{} \\
Prescribed \\
and non- \\
prescribed
\end{tabular} & $\begin{array}{l}\text { Health } \\
\text { profession } \\
\text { at visits }\end{array}$ & $\checkmark$ & $\begin{array}{c}\text { Hospital- } \\
\text { isation }\end{array}$ & $\begin{array}{c}\text { Com- } \\
\text { munity } \\
\text { services }\end{array}$ & $x$ & $x$ & $\begin{array}{l}\text { Private } \\
\text { services }\end{array}$ & $x$ & $x$ & $x$ \\
\hline
\end{tabular}

\section{Discussion}

This paper presents the first known synthesis of information on the impact of waiting for orthopaedic care for musculoskeletal complaints, in terms of costs and quality of life. This review found a moderate amount of relevant literature (17 studies), reported mostly in prospective observational or descriptive studies, of low to moderate quality. There was interest from the developed world in assessing the impact of waiting, as evidenced by research produced in nine countries. This scoping review found little information on the impact of waiting that could assist in understanding how waiting on an outpatient orthopaedic waiting list impacted on the health system, the individual or society. The papers included in the review reported heterogeneous information on the patient journey, the costs measured whilst waiting and QoL of patients whilst waiting.

Orthopaedic conditions: The literature focused entirely on osteoarthritic hips and knees, and all studies were about patients waiting for surgery. The focus on hips and knees possibly reflects the high prevalence of these conditions on public hospital waiting lists, the high cost of these joint replacements, the high prevalence of these conditions in the sociodemographics of people who require the public hospital system, and the orientation that this places on current research. $[1,4,5]$ Thus there are many gaps in current knowledge regarding the impacts of waiting for individuals suffering other orthopaedic/musculoskeletal complaints.
Realist synthesis approach: The Realist Synthesis approach [23] was helpful in assisting us to understand just where in the patient journey, the included research focused. Without this approach, it would have been more difficult to scope the research findings. A key finding from investigating QoL in this scoping review was that all but one paper (with the exception of Pace et al [41]) was focused on one time period in the patient journey, that being from the point of being placed on a surgical waiting list to varying points postoperatively (one, three, six and twelve months following surgery) (See Figure 3). This constrained a useful synthesis of information on impact of waiting, and highlighted the need for greater understanding of the stages of waiting before further research is undertaken. If the most costly or impactful stages of waiting can be identified, interventions to avert long waiting times in these priority stages of the patient journey can be developed and tested.

Alternative models of care: This body of literature did not inform current thinking about substitution of care (such as extended scope practice, or alternative treatment options (such as conservative care). Whilst there is some evidence that these alternative models of care reduce waiting times and are satisfactory to patients, $[8,47,48]$ what is unclear is how effective they are in terms of impact on quality of life and cost parameters.

Quality of life: $80 \%$ articles included in this review reported on QoL. The findings were inconclusive regarding changes in QoL whilst outpatients waited for an orthopaedic 
appointment, or for treatment. QoL can be used as a point in time measure, or an over-time measure. [49] Therefore the ability to track change in QoL over time is an important function of any QoL outcome instrument employed in waiting list research. The two QoL measures reported in this review were WOMAC and SF36.

- The WOMAC is disease specific, and is one of the most commonly-used outcome measures in arthritis research, particularly for osteoarthritis of the hip and knee. [46] WOMAC is a self-reported instrument with five items for scoring pain, two for stiffness and 17 for functional limitation. Functional tasks include stair use, standing up from sitting, getting in and out of the car, shopping, putting on and taking off socks, bending and walking. WOMAC has been widely translated and validated in other languages, although mainly for hip and knee arthritis. [50] Whilst WOMAC has been tested for conditions other than OA hip and knee, this is less common and therefore less is known about its validity for other musculoskeletal conditions. [50] The WOMAC instrument has been shown to be less sensitive to detecting change over time in some intervention-based studies. $[51,52,53,54] \mathrm{It}$ is proposed that the rigid nature of the questions may impact on sensitivity to change, particularly when compared with more open-ended measures. [51]

- The SF36 is a broadQoL measure, estimating health status in domains of vitality, physical functioning, bodily pain, general health perceptions, physical role functioning, emotional role functioning, social function and mental health. [45] It has been widely used in research internationally, on many different health conditions to evaluate individual patient's health status and compare this to population norms, research the cost-effectiveness of treatments, and monitor and compare disease burdens. However Kean et al observed that it may not be sufficiently sensitive to change and thus its validity for use in research into the impact of waiting is questionable. [55]

To better understand the subtleties of the impact of waiting on an individual's QoL, it may require engagement with the notion of Patient Related Outcome Measures (PROMs). [56,57] To date, PROMs have been used to assess effectiveness of care. Safety and patient experience (such as shared decision-making, dignity, respect, comprehensive communication) have been less well explored. [57,58] These outcome elements may well reflect the subtleties of impact of waiting on QoL and thus there appears to be room for sophisticated patient-directed outcome measures to be developed that capture individual patient experiences whilst waiting for orthopaedic care.

Costs: There was a small body of literature (four studies only) which reported on costs. Measures of cost included health, community, personal and societal costs, and productivity. Costs were measured in a variety of ways including cost diary, retrospective reflections of costs incurred whilst waiting, and purpose-built questionnaires. None of the studies used independent validation of these costs, for example there was no formal comparison with pharmacy receipts or with Medicare data sets. Only one paper reported sufficient data to inform an economic analysis of costs and benefits. [14] It was therefore not possible to synthesise the information on costs whilst waiting, and thus this scoping review highlighted this as a significant area for further research.

\section{Conclusion}

This scoping review highlighted scant and inconsistent evidence regarding the impact of waiting on cost and QoL measures, for an orthopaedic outpatient appointment. The information that is available comes from a limited patient group (hip and knee osteoarthritis). There was little evidence of the impact of waiting across the continuum of the waiting period, as studies focused on sections of the patient journey. There was no clarity regarding how the waiting time in a patient's journey could be considered, and the bulk of the literature focused on the time from when the patient is placed on the waiting list for hip or knee replacement surgery to the point of surgical intervention and subsequent rehabilitation. This means that little is currently known what went before the decision-making about the need for surgery. This review highlighted that there is little known about other types of patients referred for surgical consultation whose ultimate management is not surgery, or who proceed to surgery for a condition other than osteoarthritis of the hip or knee. Further research is required, using sensitive and defensible measures of QoL, and costs, before an understanding of the impact of waiting occurs, and before health systems can support healthcare providers to make shared and informed choices with their patients about the best management of orthopaedic complaints.

\section{Future}

Areas for improvement in future studies which assess the impact of waiting for specialist orthopaedic opinion are:

- Broadening the focus of research to other types of orthopaedic conditions. At this time the evidence 
focuses on patient with hip and knee osteoarthritis that are awaiting surgical intervention. Nothing was found in this review about the impact of waiting for specialist consultation and/or care for patients with other musculoskeletal conditions (e.g. shoulder pain, ankle problems, spinal pain and wrist/hand and elbow problems).

- Improving capture of QoL and cost outcomes. Standard agreement is required regarding the most appropriate and sensitive measures across a broad range of musculoskeletal conditions to capture the impact of waiting.

For QoL, PROMs should be considered, as well as new outcome measures to capture subtle individual concerns, particularly in measuring individual concerns about having to wait for attention for a condition that may be worsening.

For costs, valid measures of productivity costs, opportunity costs, societal costs and healthcare costs incurred by both the patient and the healthcare system are required.

- Increasing understanding of the phases of 'waiting'. Waiting is not simply about the time between the orthopaedic decision and proceeding to surgery. It includes the time between consulting a GP, being placed on an outpatient waiting list, and then waiting for an orthopaedic consultation. In the literature that is available there is a lack of consistency in the measures used to report the impact of waiting, in terms of both cost and health outcomes/QoL. In particular the different time points at which the impact of waiting is measured across the different studies, makes comparing outcomes problematic.

\section{Key findings}

Little is known about the impact of waiting for an orthopaedic specialist assessment. What evidence is available is of low hierarchy and low to moderate quality. Standardised measures of QoL and cost are required, as is a better appreciation of the waiting period, and the phases within it.

\section{Competing interests}

The authors declare that they have no competing interests.

\section{References}

1. Australian Institute of Health and Welfare. Arthritis, osteoporosis and other musculoskeletal conditions [Internet]. Canberra: AlHW; 2015. Available from http://www.aihw.gov.au/arthritis-andmusculoskeletalconditions/

2. Vos T, Flaxman AD, Naghavi M, Lozano R, Michaud C, Ezzati M, et al. Years lived with disability (YLDs) for 1160 sequelae of 289 diseases and injuries 1990-2010: a systematic analysis for the Global Burden of Disease Study 2010. Lancet. 2012;380:2163-96.

3. Cross M, Smith E, Hoy D, Nolte S, Ackerman I, March L, et al. The global burden of hip and knee osteoarthritis: estimates from the global burden of disease 2010 study (cited 6 Dec 2016). Ann Rheum Dis. [serial on the Internet] 2014;73(7):1323-1330. Available from: MEDLINE.

4. Gross J. Projection of Australian health care expenditure by disease, 2003 to 2033. Cat. no. HWE 43. Canberra: AlHW; 2008.

5. Woolf AD, Vos T, March L. How to measure the impact of musculoskeletal conditions. Best Prac Res Clin Rheumatol. 2010; 24:723-32.

6. Oldmeadow LB, Bedi HS, Burch HT, Smith JS, Leahy ES, Goldwasser M. Experienced physiotherapists as gatekeepers to hospital orthopaedic outpatient care. Med J Aust. 2007;186(12):625-628.

7. Blackburn M, Cowan S, Cary B, Nall C. Physiotherapy-led triage clinic for low back pain. Aust Health Rev. 2009;33(4):663-670. doi: 10.1071/AH090663.

8. Morris J, Grimmer-Somers K, Kumar S, Murphy K, Gilmore L, Ashman B, Perera P, Vine K, Coulter C. Effectiveness of a physiotherapy-initiated telephone triage of orthopedic waitlist patients. Patient Relat Outcome Meas. 2011;2:151-159.

9. Birch S, Mason T, Sutton M, Whittaker W. Not enough doctors or not enough needs? Refocusing health workforce planning from providers and services to populations and needs. J Health Serv Res Policy. 2013;18(2):107-113.

10. Morris JH, James RE, Waddington G, Davey R. What is orthopaedic triage? A systematic review, J Eval Clin Pract. 2015;128-136.

11. Marks D, Bisset L, Thomas M, O'Leary S, Comans T, Ng SN, Conaghan PG, Scuffman P. An experienced physiotherapist prescribing and administering corticosteroid and local anaesthetic injections to the shoulder in an Australian orthopaedic service, a non-inferiority randomised controlled trial and economic analysis: study protocol for a randomised controlled trial. Trials. 2014;503(15): 1-9.

12. Mandzuk LL, McMillan DE, Bohm ER. The bone and joint decade in Canada: a look back and a look forward. Int J Orthop Trauma Nurs. 2010;4:12-17.

13. Siciliani L, Moran V, Borowitz M. Measuring and comparing health care waiting times in OECD countries. Health Policy. 2014;118: 292-303.

14. Rolfson O, Strom O, Karrholm J, Malchau H, Garellick G. Costs related to hip disease in patients eligible for total hip arthroplasty. J Arthroplasty. 2012;27(7):1261-66.

15. Robling MR, Pill RM, Hood K, Butler CC. Time to talk? Patient experiences of waiting for clinical management of knee injuries. Qual Saf Health Care. 2009;18(2):141-146.

16. Desmeules F, Dionne CE, Belzile E, Bourbonnais R, Frémont $P$. The impacts of pre-surgery wait for total knee replacement on pain, function and health-related quality of life six months after surgery. J Eval Clin Pract. 2010a:1-10.

17. Maddison P, Jones J, Breslin A, et al. Improved access and targeting of musculoskeletal services in northwest Wales: targeted early access to musculoskeletal services (TEAMS) programme. BMJ. 2004;329(7478):1325-1327. 
18. Moloney A, Dolan M, Shinnick L, Murphy M, Wallace L. A 6-month evaluation of a clinical specialist physiotherapist's role in a fracture clinic. Physiotherapy Ireland. 2009;30(1):8-15. doi: 10.3233/PPR20009-30104.

19. Burn D, Beeson E. Orthopaedic triage: cost effectiveness, diagnostic/ surgical and management rates. Clin Gov. 2014;19(2):126-136.

20. Samsson KS, Larsson MEH. Physiotherapy triage assessment of patients referred for orthopaedic consultation - long-term followup of healthrelated quality of life, pain-related disability and sick leave. Manual Therapy. 2015;20:38-45.

21. MacKay C, Davis AM, Mahomed N, Badley EM. Expanding roles in orthopaedic care: a comparison of physiotherapist and orthopaedic surgeon recommendations for triage. J Eval Clin Pract. 2009;15(1):178-183. doi: 10.1186/14726963-8-147.

22. Joanna Briggs Institute. The Joanna Briggs Institute Reviewers' Manual 2015: methodology for JBI scoping review (cited 11 Jan 2017) . Adelaide: Joanna Briggs Institute; 2015. Available from: http://joannabriggs.org/assets/docs/sumari/Reviewers-Manual Methodologyfor-JBI-Scoping-Reviews_2015_v2.pdf

23. Pawson R, Greenhalgh T, Harvey G, Walshe K. Realist review - a new method of systematic review designed for complex policy interventions. J Health Serv Res Policy. 2005;10:21-34.

24. Merlin T, Weston A, Tooher R. Extending an evidence hierarchy to include topics other than treatment: revising the Australian 'levels of evidence'. BMC Medical Research Methodology. 2009; 9(34). doi:10.1186/1471-2288-9-34

25. Physiotherapy Evidence Database (PeDro) criteria (https://www. pedro.org.au/) [accessed 7 Jan 2017].

26. Critical Appraisal Skills Programme (CASP). CASP Checklists. Available from: (http://media.wix.com/ugd/dded87 e37a4ab637fe46a0869f9f977dacf134.pdf) Oxford 2014. CASP.

27. Hoogeboom TJ, van den Ende CHM, van der Slius G, Elings J, Dronkers, JJ, Aiken AB, van Meeteren NLU. The impact of waiting for total joint replacement on pain and functional status: a systematic review. Osteoart Cartil. 2009;17;1420-7.

28. March L, Cross M, Tribe K, Lapsley H, Courtenay B, Brooks P. Cost of joint replacement surgery for osteoarthritis: the patients' perspective. J Rheumatol. 2002;29(5):1006-14.

29. Fielden JM, Cumming JM, Fracs Horne JG, Fracs Devane PA, Slack A Gallagher LM. Waiting for hip arthroplasty: economic costs and health outcomes. J Arthroplasty. 2005;20(8):990-997

30. Ackerman IN, Bennell KL, Osborne RH. Decline in Health-Related Quality of Life reported by more than half of those waiting for joint replacement surgery: a prospective cohort study. BMC Musculoskeletal Disorders. 2011;108(12):1-9.

31. Ahmad I, Konduru S. Change in functional status of patient whilst awaiting primary total knee arthroplasty. Surgeon. 2007;5(5):266-7.

32. Chakravarty D, Tang T, Vowler SL, Villar R. Waiting for primary hip replacement - a matter of priority. Ann R Coll Surg Engl. 2005; 87:269-73.

33. Desmeules F, Dionne $C E$, Belzile $E$, Bourbonnais $R$, Frémont $P$. The burden of wait for knee replacement surgery: effects on pain function and health-related quality of life at the time of surgery. Rheumatology. 2010b; doi:10.1093/rheumatology/kep469.

34. Hirvonen J, Tuominen U, Seitsalo $S$, Lehto $M$, Paavolainen $P_{,}$ Hietaniemi K, Rissanen P, Sintonen H, Blom M. The effect of waiting time on Health-related quality of life, pain and physical function in patients awaiting primary total hip replacement: a randomized controlled trial. Value Health. 2009;12(6):942-7.

35. Kapstad H, Rustøen T, Hanestad BR, Moum T, Langeland N, Stavem K. Changes in pain, stiffness and physical function in patients with osteoarthritis waiting for hip or knee joint replacement surgery. Osteoart Cartil. 2007;15:837-43.
36. Kelly KD, Voaklander DC, Johnston DWC, Newman SC, SuarezAlmazor ME. Change in pain and function while waiting for major joint arthroplasty. J Arthroplasty. 2001;16(3):351-9.

37. McHugh GA, Luker KA, Campbell M, Kay PR, Silman AJ. Pain, physical functioning and quality of life of individuals awaiting total joint replacement: a longitudinal study. J Eval Clin Pract. 2006; 14:19-26.

38. Nilsdotter AK, Lohmander LS. Age and waiting time as predictors of outcome after total hip replacement for osteoarthritis. Rheumatology. 2002;41:1261-7.

39. Nunez M, Nunez E, Segur JM, Macule F, Quinto L, Hernandez MV, Vilalta $C$. The effect of an educational program to improve healthrelated quality of life in patients with osteoarthritis on waiting list for total knee replacement: a randomized study. Osteoart Cartil. 2006;14: 279-85.

40. Ostendorf M, Buskens E, van Stel H, Schrijvers A, Marting L, Dhert W, Verbout A. Waiting for Total Hip Arthroplasty: Avoidable Loss in Quality Time and Preventable Deterioration. J Arthroplasty. 2004;19(3): 302-9.

41. Pace A, Orpen N, Doll H, Crawford EJ. The natural history of severe osteoarthritis of the knee in patients awaiting total knee arthroplasty. Eur J Orthop Surg Traumatol. 2005;15:309-312.

42. Tuominen $U$, Sintonen $H$, Hirvonen J, Seitsalo S, Paavolainen $P_{r}$ Lehto $M$, Hietaniemi K, Blom M. The effect of waiting time on health and quality of life outcomes and costs of medication in hip replacement patients: a randomized clinical trial. Osteoart Cartil. 2009; 17:1144-1150.

43. Petersson IF, Boegård T, Saxne T et-al. Radiographic osteoarthritis of the knee classified by the Ahlbäck and Kellgren and Lawrence systems for the tibiofemoral joint in people aged 35-54 years with chronic knee pain. Ann. Rheum. Dis. 1997;56(8):493-6. doi:10.1136/ ard.56.8.493.

44. Kellgren JH, Lawrence JS. Radiological assessment of osteo-arthrosis. Ann. Rheum. Dis. 2000;16 (4):494-502.

45. Ware JE Jr, Sherbourne CD. The MOS 36 ItemShort Form Health Survey (SF 36). Conceptual framework and item selection. Medical Care. 1992;30:473-483.

46. Roos EM, Klassbo M, Lohmander LS. WOMAC osteoarthritis index Reliability, validity, and responsiveness in patients with arthroscopically assessed osteoarthritis. Western Ontario and MacMaster Universities. Scand J Rheumatol. 1999;28(4):210-215.

47. Aiken $A B$, Harrison MM, Hope J. Role of the advanced practice physiotherapist in decreasing surgical wait times. Healthc $Q$. 2009;12(3):80-83.

48. Bath B, Janzen B. Patient and referring healthcare provider satisfaction with a physiotherapy spinal triage assessment service. J Multidiscip Healthc. 2012;5:1-15.

49. Sprangers MA, Moinpour CM, Moynihan TJ, Patrick DL, Revicki DA Clinical Significance Consensus Meeting Group. Assessing meaningful change in quality of life over time: a users' guide for clinicians. Mayo Clin Proc. 2002;77(6):561-71.

50. American College of Rheumatology (http://www.rheumatology. org/IAm-A/Rheumatologist/Research/Clinician-Researchers/ Western-Ontario-McMaster-Universities-Osteoarthritis-IndexWOMAC) [accessed 7 Jan 2017].

51. Parkes MJ, Callaghan MJ, O'Neill TW, Forsythe LM, Lunt M, Felson DT. Sensitivity to change of patient-preference measures for pain in patients with knee osteoarthritis: data from two trials. Arthritis Care Res (Hoboken.) 2016;68(9):1224-1231. doi: 10.1002/acr.22823.

52. Zampelis V, Ornstein E, Franzen H, Atroshi I. A simple visual analog scale for pain is as responsive as the WOMAC, the SF-36, and the EQ-5D in measuring outcomes of revision hip arthroplasty. Acta Orthop. 2014;85:128-32. 
53. Lineker SC, Badley EM, Hawker G, Wilkins A. Determining sensitivity to change in outcome measures used to evaluate hydrotherapy exercise programs for people with rheumatic diseases. Arthritis Care Res. 2000;13:62-5.

54. Bellamy N, Campbell J, Syrotuik J. Comparative study of self-rating pain scales in osteoarthritis patients. Curr Med Res Opin. 1999; 15:113-9.

55. Kean J, Monahan PO, Kroenke K, Wu J, Yu Z, Stump TE, Krebs EE. Comparative Responsiveness of the PROMIS Pain Interference Short Forms, Brief Pain Inventory, PEG, and SF-36 Bodily Pain Subscale. Med Care. 2016;54(4):414-21. doi: 10.1097/ MLR.0000000000000497

56. Valderas JM, Kotzeva A, Espallargues M, Guyatt G, Ferrans $C E$, Halyard MY, et al. The impact of measuring patient-reported outcomes in clinical practice: a systematic review of the literature. Qual Life Res. 2008;17:179-93.

57. Black N. Patient reported outcome measures could help transform healthcare. BMJ (Clinical research ed). 2013;346. f167. ISSN 09598138 DOI: $10.1136 / \mathrm{bmj} . f 167$

58. Grosse Frie K, van der Meulen J, Black N. Relationship between patients' reports of complications and symptoms, disability and quality of life after surgery. Brit J Surg. 2012; 99:1156-63. 